\title{
UWOMJ: 25, 50, \&t 75 years ago
}

UWOMJ: 25, 50, \& 75 years ago is a new series featuring past perspectives and research of Schulich medical students as chronicled in the UWOMJ. This first edition was compiled by Chloe Gui.

\section{YEARS AGO: FALL 1993, ISSUE 63(1)}

\section{A sample of infectious diseases research in Peru \\ Ross Mantle, Meds'95}

The following is a sample of eight concurrent research projects I was exposed to when I travelled to Peru in the summer of 1992 and stayed with Professor Robert Gilman, MD of John's Hopkins University. [...] The wide diversity of tropical infective disease, coupled with the effects of altitude which can be observed in the Andes make Peru an attractive research arena for the infective disease specialist.

\section{Helicobacter pylori (HP)}

The relationship between HP, atrophic gastritis, and gastric ulcer, has been known for over five years, but is only just now becoming accepted in North American Centres. The further likely relationship between HP and gastric cancer is the subject of research effort by Dr. Gilman. In the third world HP infection rates typically see most of the population infected by age 20 , and in some places $50 \%$ of the population are infected before one year of age. Rates of gastric cancer are higher and those of peptide ulcer lower than in the first world.

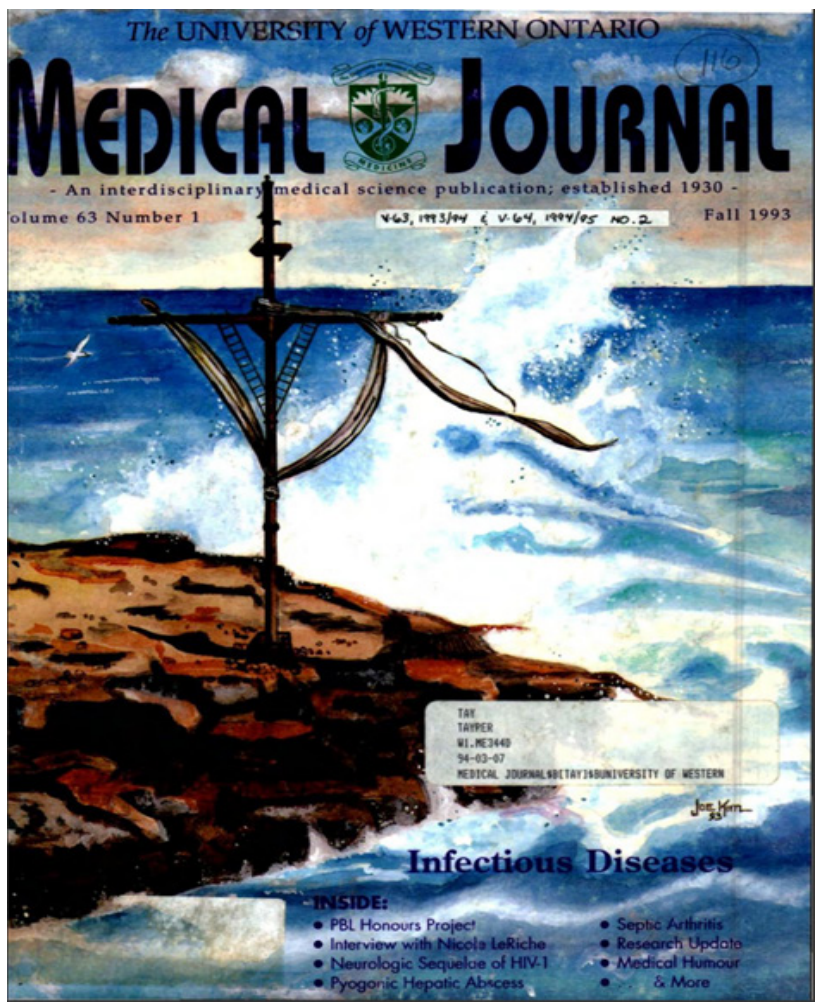

\section{YEARS AGO: FEBRUARY 1968, VOLUME 38, NUMBER 3}

\section{Prognosis: Hopeless}

Gary Koop, Meds '69

There are a multitude of once "hopeless" conditions which made life very disagreeable to the patient at one time. It is quite safe to say that if euthanasia had been practiced in the past, our knowledge of these diseases would have come to a standstill and they would still be a source of human woe. Medicine says we must buy time; euthanasia says that the price of time is too high for what it is worth. It seems that medicine stops when euthanasia starts, and the latter can never be appropriate as one of the treatments to be used in the former.

\section{[...]}

There is a strong movement in favour of permission legislation on euthanasia in the Western democracies. The threat to the practice of medicine here comes not from politician interest on fulfilling certain goals of the state, but primarily from philosophies intent upon the preservation of the "good life". The primary element of this supposed "good life" is freedom from pain. When we see what a large section of medical practice is devoted to the relief of pain, it would seem that we have accepted the philosopher's definition of "the good life". However, the larger goal of preservation of life is always foremost as is evident in our definition of the ideal analgesic (which, incidently [sic], has not yet been discovered).

\section{CAMSI Centennial Exchange, Inuvik, N.W.T.}

Robert Birnbaum ' 69

On August 12, 1967, 70 medical students, representing each of Canada's 12 medical schools, met in Edmonton, Alta., for the beginning of the 2 nd annual CAMSI summer school. This being our Centennial year, the summer school was to be held in Canada. The topic - 'Frontier Medicine'. The frontier - Canada's Arctic.

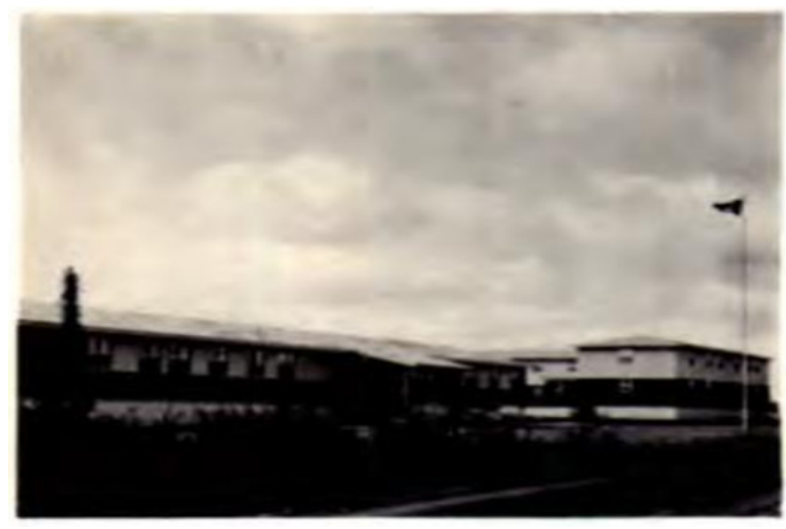

Inuvik Hospital 


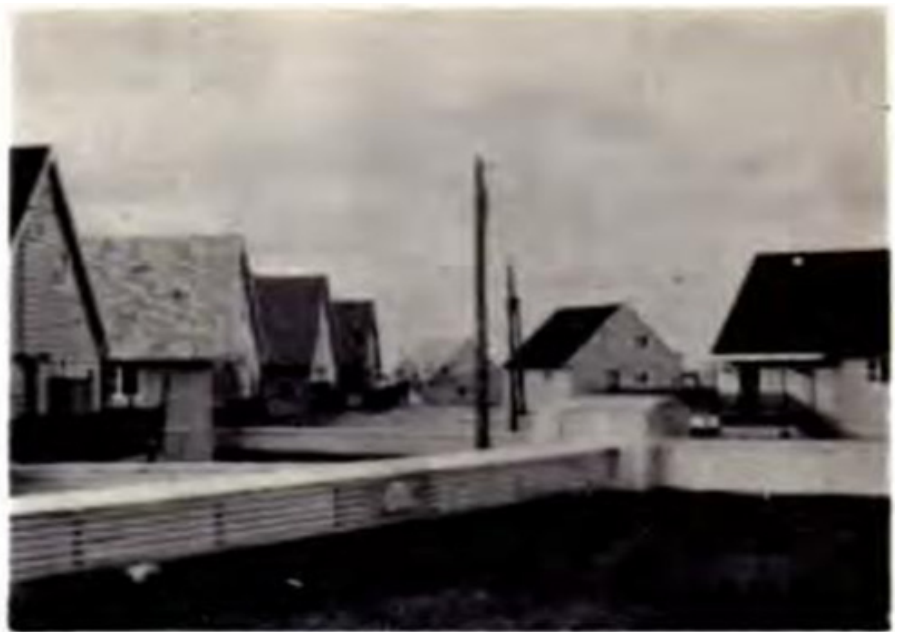

Above: The 'Utilidor', below: Inuvik Eskimos [sic]

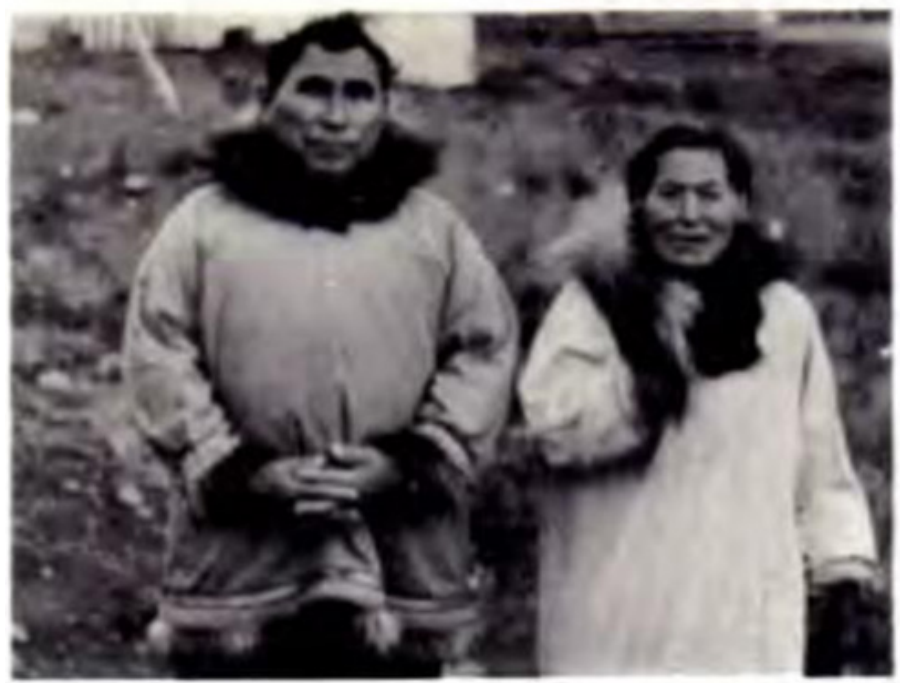

\section{YEARS AGO: MARCH 1943, VOLUME 13}

\section{Wartime Abdominal Injuries}

Charles Dyson

Since the Battle of France in 1940, military surgeons of the United Nations have had relatively limited opportunities (with the exception of those in attendance upon the North African, Russian or Chinese forces) to deal with abdominal injuries sustained upon the field of battle. Nothing in this war has yet been seen by the majority of our surgeons which could parallel the total casualties of the pitched week- or month-long battles of World War I. However, the present conflict has presented him with a new field of endeavour, for he must not only minister to the men who have been (and will be) injured on the field of battle, but he must also reckon with the injuries which total war visits upon the civilian population. As regards the latter group, the most fertile source of information is the English journals, whose writers have had extensive experience with casualties resulting from the indiscriminate bombings in the blitz of 1940 .

A classification of wartime abdominal injuries divides them into four groups. This classification is intended only for convenience of discussion, and it should be remembered that considerable overlapping is possible:

(1) Immersion blast injuries

(2) Abdomino-thoracic injuries

(3) Non-penetrating wounds of the abdomen

(4) Wounds of the abdomen penetrating the cœlom.

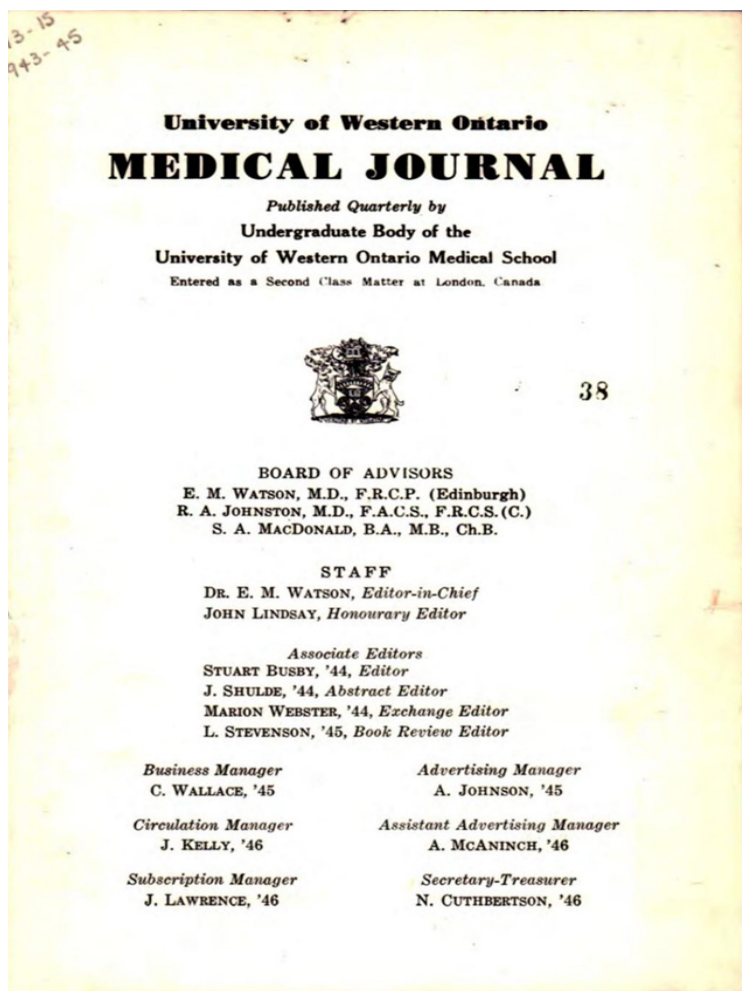

